(U) $O$ Observatori de

Bioètica i Dret

ISSN: 1886-5887

\section{Revista de Bioética y Derecho}

Publicación del Máster en Bioética y Derecho uww.bioeticayderecho.ub.es

DESDE EL MÁSTER

\title{
La importancia de la voluntad procreacional en la nueva categoría de filiación derivada de las técnicas de reproducción asistida
}

\begin{abstract}
ELEONORA LAMm ${ }^{*}$
En esta sección tienen cabida las aportaciones de los alumnos del Máster en Bioética y Derecho de la Universitat de Barcelona, de la presente edición (XIV Promoción 2011-2012) así como de ediciones anteriores. Esperamos vuestras contribuciones en obd2@pcb.ub.es.
\end{abstract}

Tabla de contenidos

1. La necesidad e influencia de la bioética en el nuevo derecho de familia surgido como consecuencia de las nuevas tecnologías reproductivas.

2. La problemática de la filiación derivada de las TRA.

3. Hacia una vuelta al criterio de verdad voluntaria

4. Su recepción legal

5. Filiación derivada de las TRA: un tercer tipo de filiación?

Diferencia con la filiación por naturaleza

Diferencia de la filiación por adopción

Filiación derivada de las TRA

6. Palabras finales

\footnotetext{
* Eleonora Lamm. Abogada. Doctora en Derecho, con línea de investigación en Bioética, por la Universidad de Barcelona. Máster en Bioética y Derecho y Máster en Derecho de Familia por la Universidad de Barcelona. Miembro del Observatorio de Bioética y Derecho (UB). Becaria del CONICET. elelamm@gmail.com

${ }^{1}$ Agradezco la invalorable colaboración de Esther Farnós Amorós.
} 


\title{
Resumen
}

Este artículo tiene por objeto analizar la problemática generada por la nueva categoría de filiación surgida como consecuencia de las TRA. Se estudia cuál es la situación legal de esta nueva filiación en España conforme la actual LTRHA y la nueva ley de Registro Civil, y cuáles son los conflictos legales que se plantean. También se la distingue de las otras dos clases de filiación existentes, precisando sus características propias y especificidades y se pone énfasis en la necesidad de que sea abordada y regulada de manera autónoma en el CC.

Palabras clave: filiación; técnicas de reproducción asistida; voluntad; consentimiento.

\begin{abstract}
This article aims to analyze the problems raised by the new category of affiliation emerged as a result of the use of ART. It is studied which is in Spain the legal status of this new affiliation according to the current LTRHA and the new Civil Registry Law, and its legal disputes. This new affiliation is also distinguished from the other two existing classes, specifying their own characteristics and emphasizing the need to be addressed and regulated independently in the Civil Code.
\end{abstract}

Key words: affiliation; assistide reproductive techniques; voluntarity; consent. 


\section{La necesidad e influencia de la bioética en el nuevo derecho de familia surgido como consecuencia de las nuevas tecnologías reproductivas}

Una de las características de los tiempos en que vivimos, es que las relaciones familiares están siendo objeto de profundos y permanentes cambios; que han tenido consecuencias en todo el derecho familia. Si bien este derecho ha estado siempre en constante evolución, los cambios a los cuales se enfrenta actualmente, como consecuencia de las nuevas tecnologías reproductivas, van más allá: lo transforman. Muchas de sus figuras jurídicas han cambiado radicalmente, no siendo ya las que eran. A su vez, muchos de los conceptos "clásicos" del derecho de familia han quedado obsoletos o se han visto desbordados como consecuencia de estas nuevas formas de reproducción.

Concretamente en materia de filiación, las técnicas de reproducción asistida (en adelante, TRA) han generado lo que se conoce como "revolución reproductiva", debido a que estas técnicas separan, radicalmente, la reproducción humana de la sexualidad. Así, hoy en día, y gracias a las TRA, es posible la reproducción sin sexo; ${ }^{2}$ lo que viene a plantear una problemática que desborda las estructuras jurídicas existentes.

Esta reproducción sin sexo que posibilita las TRA ha ampliado los tipos de familia. Las TRA permiten ser padres a quienes no podían serlo; habilitan paternidades y/o maternidades inconcebibles o imposibles años atrás, tales como la maternidad de mujeres estériles, la paternidad de hombres estériles, la maternidad sin paternidad, la paternidad sin maternidad, la paternidad y/o maternidad de ambos miembros de una pareja homosexual, ${ }^{3}$ Incluso posibilitan la maternidad de mujeres a edades muy avanzadas ${ }^{4}$. Además, las nuevas técnicas reproductivas han abierto las puertas a una planificación de la reproducción que permite evitar la transmisión de enfermedades congénitas, decidir el momento en el que se quiere tener hijos, el sexo de los mismos ${ }^{5}$, etc. ${ }^{6}$ Así, hoy en día, un creciente número de parejas fértiles, con un historial familiar de serias enfermedades está optando por recurrir al diagnóstico genético preimplantacional (DGP) ${ }^{7}$ para asegurarse de que ninguno de sus

\footnotetext{
${ }^{2}$ También como consecuencia de esta revolución, es posible el "sexo sin reproducción" en virtud del cambio en el rol social de la mujer que condujo a la aparición y uso de los distintos métodos anticonceptivos.

${ }^{3}$ Salvo en los casos de adopción (y en los países en los que ella está permitida), no tendrían acceso a la paternidad/maternidad, de no ser por estos avances

${ }^{4}$ El primer caso se presentó en el año 1994, cuando la italiana Rosanna Della Corte dio a luz a los 63 años gracias a la implantación de un óvulo procedente de donante anónima.

5 Véase OBSERVATORIO DE BIOÉTICA Y DERECHO DE LA UNIVERSIDAD DE BARCELONA. Documento sobre selección de sexo. CASADO, M. (Coord.) Signo. Barcelona. 2003. Disponible en:

http://www.pcb.ub.es/bioeticaidret/archivos/documentos/Seleccion_de_sexo.pdf. Compulsada el 27/08/2010

${ }^{6}$ ALKORTA IDIÁKEZ, I. Regulación jurídica de la medicina reproductiva. Derecho español y comparado. Thomson Aranzadi. Navarra. 2003, pp. 169

7 Entre otros, el DGP está regulado en: Francia: art. 2141-2 y 2131-4 del código de la salud de Francia, modificados por ley n²011-814 del 7/7/2011; España: art. 12 de la 14/2006 sobre Técnicas de reproducción humana asistida (en adelante LTRHA); Portugal: art. 28 de la ley n. o 32/2006, de 26 de Julio; Brasil: Resolución brasilera № 1.957, del 15 de diciembre de 2010 del Consejo Federal de Medicina; Noruega, art. 2.14 de la Ley sobre el uso médico de la biotecnología; Reino Unido. Human Fertilisation and Embryology Act. (HFEA).
} 
hijos heredará la enfermedad o, en los casos de DGP "extensivo" para seleccionar el embrión compatible con el hijo enfermo.

De esta manera, las TRA demandan cambios en la normativa vigente relativa a la filiación, debido a que amplían las opciones de reproducción y cuestionan, las nociones tradicionales de paternidad, maternidad, embarazo ${ }^{8}$ así como también la del parto ${ }^{9}$. Los rápidos y permanentes cambios científicos y tecnológicos en el ámbito de la reproducción asistida requieren de la ley para desarrollar soluciones justas y lógicas a los problemas que surgen cuando los derechos de las personas entran en conflicto con las nociones tradicionales de familia. De hecho, y como consecuencia de estos cambios, los juristas se han visto obligados a repensar el concepto de familia, así como también se han visto obligados a revisar el concepto de filiación. Revisión que si bien se traduce en términos jurídicos, corresponde efectuar también desde una perspectiva bioética. La complejidad de la nueva situación hace que el derecho por sí sólo no logre abarcar y comprender estos cambios, y es allí donde la bioética colabora con éste cumpliendo un rol fundamental.

En el derecho de familia todas estas nuevas situaciones creadas por las nuevas tecnologías (nuevos modelos de familia, distintas filiaciones, reproducción sin sexo, sexo sin reproducción, nuevas posibilidades de reproducción, planificación eugenésica de la reproducción, etc.) generan cambios que encierran planteamientos éticos importantes ante los que la mirada jurídica no basta, sino que se requiere de una mirada multidisciplinar. Se trata de problemas que, al no tener una respuesta social unívoca, desembocan en una demanda de legislación y eso deviene una típica cuestión de axiología jurídica: cuáles son los valores que debemos proteger y cómo debe hacerse. ${ }^{10}$ La decisión jurídica que se adopte, debe elaborarse previo debate bioético, que implica que ha habido una valoración y una decisión consensuada multidisciplinar en cuanto a los planteamientos éticos.

Además, si bien la filiación desde siempre ha sido un tema tratado por el derecho civil, por las razones dichas, la nueva filiación que, como se verá, sostengo ha surgido como consecuencia del uso de la TRA no puede ser plenamente abarcada y comprendida desde esta sola disciplina: En el campo jurídico, estas técnicas sitúan al derecho de filiación ante un nuevo umbral, ya que al tratarse de relaciones nuevas, la homologación crea múltiples dificultades y polémicas sobre su tratamiento,

\footnotetext{
${ }^{8}$ Hoy, gracias a las TRA es posible el embarazo sin que medie acto sexual, lo que permite el embarazo de mujeres a edades avanzadas; de mujeres solas; con óvulos provenientes de otra mujer o con material genético masculino proveniente de una persona distinta de su pareja; o incluso el embarazo de una mujer (con o sin óvulos propios) para concebir un hijo para una pareja "comitente" heterosexual u homosexual o para otra persona (maternidad subrogada).

9 La máxima del derecho romano que expresa "Mater semper certa est", consagrando, de este modo, la atribución de la maternidad por el hecho del parto, ha sido conmovida cuando la ciencia posibilitó que sea una mujer extraña a la autora genética la que llevase a cabo la gestación y el trabajo de parto. En otras palabras, ha comenzado a cuestionarse la noción de parto como determinante de la maternidad.

${ }^{10}$ OBSERVATORIO DE BIOÉTICA Y DERECHO DE LA UNIVERSIDAD DE BARCELONA. Reedición y análisis del impacto normativo de los documentos del Observatorio de Bioética y Derecho sobre reproducción asistida. CASADO, M. (Coord.) Signo. Barcelona. 2008. Disponible en:

http://www.pcb.ub.es/bioeticaidret/archivos/documentos/Reedicion_Reprod-Asistida.pdf. Compulsado el 17-072011.
} 
aumentando la importancia de la voluntad, y disminuyendo el valor de la realidad biológica ${ }^{11}$ o genética.

En otras palabras, esta revolución reproductiva surgida a partir de las TRA genera la necesidad de una concepción, análisis y estudio no solo jurídico, sino también bioético de las nuevas relaciones de filiación que surgen en su consecuencia.

\section{La problemática de la filiación derivada de las TRA}

No obstante los numerosos cambios provocados por las TRA la determinación de la filiación de las personas nacidas por el empleo de estas técnicas es, posiblemente, la cuestión más importante que plantea su utilización y en la que las normas hasta ahora vigentes se muestran más insuficientes. ${ }^{12}$.

Las TRA han introducido cambios sustanciales que inciden directamente sobre el sentido de la regulación de la filiación actualmente vigente. ${ }^{13}$ La relación jurídica derivada de las TRA no es la filiación que hasta ahora se conocía ni la paternidad/maternidad predicables son las que el Derecho occidental de Roma hacia acá, y la cultura universal, habían elaborado. ${ }^{14}$

Por lo tanto, es necesario conceptualizar ex novo el orden familiar establecido.

\section{Hacia una vuelta al criterio de verdad voluntaria}

Antes de la aparición de las TRA, sólo existía la procreación por medios naturales, a través del coito. Consecuentemente, aquel que dejaba embarazada a la mujer, era necesariamente el mismo que aportaba el material genético y la mujer que gestaba el niño en su vientre lo hacía siempre con propios óvulos. Es decir, lo biológico necesariamente comprendía lo genético, ante la imposibilidad de disociarlo.

Hoy, como consecuencia de la aparición de las TRA, lo biológico ya no comprende lo genético, ${ }^{15}$ ni lo genético comprende lo biológico ${ }^{16}$. En otras palabras hoy el aporte puede ser exclusivamente genético.

\footnotetext{
${ }^{11}$ FÁBREGA RUIZ, C. F. Biología y filiación. Aproximación al estudio jurídico de las pruebas biológicas de paternidad y de las técnicas de reproducción asistida. Comares. Granada, 1999, pp. 84.

${ }^{12}$ SERRANO ALONSO, E. “Aspectos de la fecundación artificial”. Actualidad Civil. Núm. 107. 1999, pp. 393

${ }^{13}$ BERCOVITZ RODRIGUEZ CANO, R. "La filiación inducida y las clasificaciones legales". Ponencia presentada al II Congreso Mundial Vasco, celebrado en Vitoria (28-IX a 2-X-1987), en La filiación a finales del siglo XX. Problemática planteada por los avances científicos en materia de reproducción humana. Editorial Trivium. Madrid. 1988, pp. 118.

${ }^{14}$ RIVERO HERNÁNDEZ, F. “La investigación de la mera relación biológica en la filiación derivada de fecundación artificial". Ponencia presentada al II Congreso Mundial Vasco, celebrado en Vitoria (28-IX a 2-X-1987), en La filiación a finales del siglo XX. Problemática planteada por los avances científicos en materia de reproducción humana. Editorial Trivium. Madrid. 1988, pp. 142.

${ }^{15}$ Por ejemplo: mujer que acude a la donación de óvulos o los casos de maternidad subrogada gestacional.

${ }^{16}$ Puede suceder que una persona aporte únicamente material genético (por ej. donación de semen) o que se
} 
Entonces, si antes se distinguía entre biológico y voluntario, hoy se presentan tres criterios perfectamente diferenciados lo genético, lo biológico y lo voluntario.

Ahora bien, como las TRA permiten que el aporte sea puramente genético, cuando se trata de filiación derivada de las TRA el aporte en general ${ }^{17}$ deja de ser biológico (como sucedía en la procreación natural) ${ }^{18}$, para comenzar a ser puramente genético. Entonces, mientras que en la filiación por naturaleza el conflicto es entre lo biológico y lo volitivo, en la filiación derivada de las TRA el conflicto es entre lo genético y lo volitivo. Ahora bien, lo biológico importa un plus respecto de lo genético $^{19}$; y como lo genético carece de ese plus adquiere más importancia y relevancia lo volitivo. ${ }^{20}$ En definitiva, el elemento volitivo adquiere importancia superlativa en la filiación derivada de las TRA, de modo que cuando en una misma persona no coinciden el elemento genético, el biológico y el volitivo, se debe dar preponderancia al último. Prevalece la paternidad consentida y querida, por sobre la genética.

Se está ante nuevas realidades que importan una "desbiologización y/o desgenetización de la filiación", y en cuya virtud el concepto de filiación ganó nuevos contornos comenzándose a hablar de "parentalidad voluntaria" o "voluntad procreacional".

Lo expuesto demuestra que si durante años la lucha se dirigió al triunfo de la verdad biológica (recuérdese la derogación de la prohibición de investigar la paternidad que existía en el derecho español), hoy se ha dado una vuelta de página. Las TRA han provocado una nueva vuelta a la verdad voluntaria en la que la filiación ya no se determina por el elemento genético o biológico, sino por el volitivo.

Si bien las TRA son utilizadas, en general, por aquellos que no quieren renunciar a tener un hijo "genéticamente propio", no es el elemento genético el que determina la filiación, sino el volitivo. Conforme se verá luego, se trata de una filiación que se determina sobre la base del consentimiento previamente prestado.

utilice material genético del hombre que quiere tener un hijo, pero el embarazo se produzca a través de las TRA.

${ }^{17}$ Digo en general, porque entiendo que deben hacerse precisiones cuando se trata de supuestos de maternidad subrogada o cuando es la mujer la que recurre a material genético de otra aportando la gestación.

${ }^{18}$ El embarazo de la mujer ya no se produce a través del coito, sino que se recurre a las TRA. De esta manera, como el embarazo ya no es consecuencia del acto sexual, su aporte será genético o volitivo - o los dos- pero no biológico.

${ }^{19}$ Lo biológico importa un plus respecto de lo genético dado que irroga un vínculo entre el nacido y quienes lo procrearon que va más allá del aporte genético. El origen cuenta con una producción: alguien estuvo allí para producirlo y ese alguien está más allá de los genes.

${ }^{20}$ ¿Quién es el padre? ¿El donante que aportó material genético o el que quiso tener el niño? 


\section{Su recepción legal}

Esta importancia del elemento volitivo en la filiación derivada de las TRA ha llevado a que muchas legislaciones, incluida la española, lo regulen como el determinante de ésta. ${ }^{21}$

4.1. Situación legal actual. Ley 14/2006, de 26 de mayo, sobre técnicas de reproducción humana asistida. (LTRHA) ${ }^{22}$

Tratándose de una pareja heterosexual casada que acude a las TRA heterólogas ${ }^{23}$, la actual redacción de la LTRHA, en su art. 8.1 establece que "Ni la mujer progenitora ni el marido, cuando hayan prestado su consentimiento formal, previo y expreso a determinada fecundación con contribución de donante o donantes, podrán impugnar la filiación matrimonial del hijo nacido como consecuencia de tal fecundación." Según esta disposición, si se consintió no se puede impugnar alegando no ser quien aportó el material genético; o sea, que el vínculo filial queda determinado por el consentimiento previamente prestado - con las formalidades previstas en el art. 6.3 LTRHA $^{24}$ - con prescindencia del elemento genético o biológico. ${ }^{25}$

Ahora bien, por tratarse de una pareja heterosexual casada, y conforme al art. 7.1 de la LTRHA que remite a las reglas de la filiación civil, en estos casos la paternidad del marido quedará determinada mediante la presunción de paternidad del art. $116 \mathrm{CC} .{ }^{26}$ Se recurriría al escrito de consentimiento si se pretendiera impugnar esa paternidad, lo que demuestra que en definitiva el vínculo queda determinado sobre la base de este consentimiento y no de la presunción, que por lo demás no se aplica a las parejas homosexuales casadas, ${ }^{27}$ por lo que sería conveniente prever

\footnotetext{
${ }^{21}$ Véase entre otros, el art. 256 del Código Civil suizo; el art. 311-20 modificado por la Ordenanza n²005-759 del 4/7/2005 de la legislación francesa; el art. 35 de la HFEA; el art 20 de la ley portuguesa no 32/2006, del $26 / 07 / 2006$. Incluso la ley más restrictiva del derecho europeo como lo es la ley italiana 40/2004, que si bien prohíbe las TRA heterólogas, previendo una multa de entre 300.000 y 600.000 euros, establece que si a pesar de dicha prohibición se realiza este tipo de técnicas, el cónyuge o el conviviente cuyo consentimiento ha sido recibido, no puede ejercitar acciones de desconocimiento o impugnación de la paternidad.

22 Dada la amplitud y aristas del tema, por razones de espacio, en este trabajo me limitaré a exponer de manera concisa, sólo los principales rasgos y problemáticas que plantea el sistema de la LTRHA.

${ }^{23}$ Se habla de TRA heterólogas cuando se utiliza material genético de un tercero distinto de la pareja o persona que recurre a las TRA y de TRA homólogas cuando se utiliza el material genético de quienes acuden a las TRA.

${ }^{24}$ El Art. 6.3 de la LTRHA que establece: "El consentimiento del cónyuge, prestado antes de la utilización de las técnicas, deberá reunir idénticos requisitos de expresión libre, consciente y formal." Se trata de un consentimiento prestado en documento sanitario.

25 Así, para atribuir la filiación, en las TRA heterólogas la voluntad debe expresarse a través de los consentimientos exigidos legalmente, ya que de lo contrario no hay fundamento para atribuir con carácter definitivo el estatus legal de padre o madre al hombre o la mujer que no ostenta vínculo genético alguno con el nacido. FARNÓS AMORÓS, E. “Acceso a la reproducción asistida por parejas del mismo sexo en España: estado de la cuestión, propuestas y retos". Revista de Derecho de Familia. Núm. 49. Mayo 2011, pp. 153-181.

${ }^{26}$ Esta solución se afianza por lo previsto también en el inc. 2 del art. 7 que establece: “En ningún caso, la inscripción en el Registro Civil reflejará datos de los que se pueda inferir el carácter de la generación."

${ }^{27}$ Si bien la ley 13/2005 ha dejado incólume toda la regulación del régimen legal de la filiación (Art. 112 a 141

CC) subsiste no obstante la referencia al binomio formado por el marido y la mujer en los artículos 116,117 y
} 
directamente al consentimiento como el título que determina la filiación y regularlo de manera uniforme para todos los casos: $^{28}$ TRA homólogas ${ }^{29}$ y heterólogas, parejas casadas y no casadas, heterosexuales y homosexuales, como se verá luego.

Tratándose de parejas heterosexuales no casadas, la determinación de la filiación sobre la base del consentimiento previamente prestado en las TRA heterólogas está regulado en el art. 8.2 que establece: "Se considera escrito indubitado a los efectos previstos en el artículo 49 de la Ley del Registro Civil el documento extendido ante el centro o servicio autorizado en el que se refleje el consentimiento a la fecundación con contribución de donante prestado por varón no casado con anterioridad a la utilización de las técnicas." Aunque el artículo nada diga, este consentimiento también debe reunir los requisitos de expresión libre, consciente y formal, previstos en el art. $6.3^{30}$ para el marido, mas como se advierte, la LTRHA prevé distintos requisitos según se trate de una pareja casada o no.

En lo que respecta a la determinación de la filiación, tampoco en estos casos el consentimiento para someterse a las TRA constituye un título nuevo de determinación extrajudicial de la filiación no matrimonial, sino que tan solo permite iniciar el expediente registral que en su caso conducirá a la

118 del Código Civil, ya que los supuestos de hecho a los que se refieren estos artículos sólo pueden producirse en el caso de matrimonios heterosexuales.

${ }^{28}$ Esto es lo que sucedió en Cataluña. El CCCat consolida la posibilidad de consentir las TRA por parte del hombre o la mujer, casado o no con la madre. El preámbulo de la ley 25/2010, que reforma el libro segundo del CCCat, relativo a la persona y la familia explica que "Como la posibilidad de que la maternidad de la esposa o compañera que consiente la fecundación asistida de la que será la madre biológica se determine directamente afecta a los medios de determinación de la filiación, ha sido preciso añadir el consentimiento para la procreación asistida a la lista de títulos de atribución de la filiación". De esta manera, el nuevo artículo 235-3 relativo a la "Determinación" establece: “La filiación por naturaleza, con relación a la madre, resulta del nacimiento; con relación al padre y la madre puede establecerse por el reconocimiento, por el consentimiento a la fecundación asistida de la mujer, por el expediente registral o por sentencia, y, únicamente con relación al padre, por el matrimonio con la madre". Además, el CCCat. en los art- 235-8 y 235-13 confiere el mismo tratamiento y demanda los mismos requisitos para todo hombre o mujer, con independencia de su estado civil. No distingue entre parejas casadas o no, ni entre heterosexuales u homosexuales. Todos pueden consentir en documento sanitario o en documento público.

${ }^{29}$ También en los casos de parejas casadas que recurren a las TRA homólogas la filiación debería determinarse por el consentimiento previamente prestado - como título propio - y no por la presunción de paternidad. Recurriendo a la analogía: si en la filiación por naturaleza el marido puede impugnar la paternidad cuando no es el padre biológico, en la filiación derivada de las TRA, fundada en el elemento volitivo, el marido podría impugnar la paternidad no consentida; de lo que se desprende que no se debería imponer la paternidad al marido que no consintió, aunque se haya utilizado - obviamente sin su consentimiento - su material genético, debiendo ser directamente el consentimiento el título de atribución de la paternidad. Cabe aclarar que no es esta la solución que adopta el CCCat. que en su art. 235.28 establece: "Si la filiación se deriva de la fecundación asistida de la madre, la acción de impugnación no puede prosperar si la persona cuya paternidad o maternidad se impugna consintió la fecundación de acuerdo con los artículos 235-8 o 235-13, y tampoco, en ningún caso, si es progenitor biológico del hijo." Es decir, aunque no haya consentido, no procede la impugnación si se ha utilizado su material genético. Tampoco prevén la posibilidad de impugnar las TRA homólogas no consentidas las legislaciones de Francia, Suiza, Reino Unido, entre otras.

${ }^{30}$ ALKORTA IDIÁKEZ, I. “Regulación jurídica de la medicina...” op. Cit, pp. 241 
declaración de la paternidad conforme lo dispuesto por el art. 120 CC que permite determinar legalmente la filiación no matrimonial por resolución recaída en expediente tramitado con arreglo a la legislación del Registro Civil. ${ }^{31}$ Actualmente, en la práctica, generalmente se recurre al reconocimiento (art. $120.1 \mathrm{CC})^{32}$ a los efectos de determinar la filiación, como si se tratara de un caso de filiación por naturaleza. ${ }^{33}$ Ahora bien, si se planteara una acción de impugnación de la paternidad, esta prosperaría porque no habrá vínculo biológico, ${ }^{34}$ de allí nuevamente la necesidad de que el consentimiento sea regulado directamente como el título determinante de la filiación. ${ }^{35}$

No obstante lo dicho, como se verá luego, con la entrada en vigor de la nueva ley del Registro Civil el art. 8.2 quedará vacío de contenido.

Tratándose de matrimonios homosexuales compuestos por dos mujeres, la LTRHA en su art. 7.3 establece que la filiación de la otra mujer se determina sobre la base del consentimiento previamente prestado, que, a su vez, permite determinar la maternidad con independencia del vínculo genético entre la mujer y el hijo. ${ }^{3637}$

Ahora bien, la prestación del consentimiento por la mujer cónyuge de la madre requiere un acto positivo que es diferente y más complejo que el que la ley exige al marido que quiere que quede determinada su paternidad respecto del nacido. Mientras que éste puede consentir a la determinación de la paternidad a su favor en el mismo documento sanitario (art. 6.3 LTRHA), sin perjuicio de que la filiación quedará inicialmente determinada por el juego de la presunción de paternidad matrimonial

${ }^{31}$ FARNÓS AMORÓS, E. Tesis doctoral "Ruptura del projecte parental i disposició dels preembrions", defendida el 5 de mayo de 2010 en la Universitat Pompeu Fabra, pp. 1-594: http://www.tesisenred.net/TESIS_UPF/AVAILABLE/TDX-0902110-085844//tef.pdf

${ }^{32}$ Como se vio, en Cataluña no es necesario el reconocimiento, debido a que se añadió el consentimiento para la procreación asistida a la lista de títulos de atribución de la filiación.

${ }^{33}$ También puede iniciarse el expediente registral a que se refiere el art. 120.2 CC. La tramitación y resolución del expediente sin oposición del Ministerio Fiscal ni de la parte interesada permitirá establecer extrajudicialmente la paternidad. FARNÓS AMORÓS, E. Tesis doctoral "Ruptura del projecte ..." op. Cit

${ }^{34}$ FARNÓS AMORÓS, E. Tesis doctoral "Ruptura del projecte ..." op. Cit.

${ }^{35}$ Además, admitir el reconocimiento a los efectos de determinar la filiación sin reparar en que se recurrió a las TRA heterólogas - aunque no importe lo genético a los efectos de la filiación en este caso - atenta contra la identidad del niño.

${ }^{36}$ Solución que cambia absolutamente la noción tradicional de maternidad. Esto es así, porque puede que una de las mujeres haya aportado su gestación y haya parido, pero puede que lo haya hecho con óvulos de la otra mujer o donados - no con los suyos propios - lo que ya representa un cambio. Pero además, la otra mujer es legalmente madre con la sola aportación del elemento volitivo. Esta segunda mujer no ha gestado, ni por ende parido, y puede que ni siquiera haya aportado su óvulo y aún así, hoy es madre por haberlo así consentido. Como se puede advertir, se trata de una noción de maternidad que se aparta de las estructuras tradicionales.

${ }^{37}$ La determinación de la filiación de la segunda mujer sobre la base del consentimiento previamente prestado también ha sido adoptada en el Reino Unido (Art. 43 y 44 de la HFEA); Bélgica. (Loi relative à la procréation médicalement assistée et à la destination des embryons surnuméraires et des gamètes); Suecia. (ley SFS 2005:434); Noruega (Ley sobre el uso médico de la biotecnología); Islandia, (Act on Artificial Fertilisation and use of Human Gametes and Embryos for Stem-Cell Research); Australia. (AUST J. FAM. LAW 160 (2009)); entre otros. 
(art. $116 \mathrm{CC}),{ }^{38}$ la mujer que pretende que su maternidad quede determinada debe llevar a cabo una manifestación expresa previa al nacimiento ante el Encargado del Registro civil del domicilio conyugal. ${ }^{39}$ Coincido plenamente con quienes sostienen que tales distinciones son discriminatorias y contrarias al espíritu de la Ley 13/2005, de matrimonio homosexual. ${ }^{40}$

Además, la LTRHA, sólo habla de "mujer casada", por lo que sólo contempla la posibilidad de determinar la filiación sobre la base del consentimiento para el supuesto de parejas casadas, lo que evidencia que la ley se quedó a mitad de camino. ${ }^{41}$ Esta falta de contemplación de las parejas de mujeres no casadas es injusta debido a que, tratándose de una pareja heterosexual no casada, aunque con los matices expuestos, es suficiente el consentimiento expresado en documento sanitario (art. 6.3 y 8.2 LTRHA), en cambio, si es una pareja de hecho homosexual, aunque la situación sea idéntica - ausencia en ambos casos de aporte de material genético - la ley, en este segundo caso, obliga a la otra mujer a adoptar... dependiendo el éxito de la adopción, muchas veces, del criterio del juez. Pero además, ¿Qué pasaría con el niño y la segunda mujer si antes de que se logre la adopción la madre legal fallece? O si en ese tiempo estas mujeres se separan. Sin perjuicio de los costos y el tiempo que demanda el proceso de adopción. ${ }^{42}$

Ahora bien, no obstante las deficiencias del sistema de la LTRHA que, como se verá, evidencian aún más la necesidad de que la filiación derivada de las TRA sea expresamente regulada en el CC, de lo dicho se desprende que, en la filiación derivada de las TRA, lo que funda la filiación jurídica no es la capacidad reproductiva (el elemento biológico) sino la voluntad (el elemento volitivo). Las TRA nos obligan a asumir un sistema de filiación fundado en la voluntad respecto de la mujer o el hombre que, independientemente del aporte de material genético, consiente las TRA de la mujer que concibe y da a luz.

\footnotetext{
${ }^{38}$ Presunción que, como se dijo, no rige para los casos de matrimonios homosexuales.

${ }^{39}$ FARNÓS AMORÓS, E. “Acceso a la reproducción asistida...” op. cit, pp. 153-181.

40 Véase SÁNCHEZ HERNÁNDEZ, A. “La feminización del derecho privado y las técnicas de reproducción asistida", en LÓPEZ DE LA CRUZ, L. y OTERO CRESPO, M. (Coord.) y GARCÍA RUBIO, M. P. y VALPUESTA FERNÁNDEZ, M. (Dir.), El levantamiento del velo: las mujeres en el derecho privado, Valencia, Tirant lo blanch, 2011, pp. 691. FARNÓS AMORÓS, E. Tesis doctoral “Ruptura del projecte ...” op. Cit

${ }^{41}$ Distinto es lo que sucede en Cataluña. El CCCat en el art. 235-13 expresamente permite la determinación de la maternidad de la mujer que consiente la aplicación de TRA de su compañera sobre la base del consentimiento previamente prestado.

${ }^{42}$ Además, esta medida también se alinearía con la posibilidad de determinar la doble filiación a favor de las parejas homosexuales, admitida desde la entrada en vigor de la Ley $13 / 2005$, del matrimonio homosexual, con el reconocimiento de la adopción conjunta por los cónyuges homosexuales y, en especial, desde la opción que ofrecen CC.AA. como Cataluña, País Vasco y Navarra a los convivientes homosexuales, a fin de determinar la doble filiación por la vía de la adopción conjunta. FARNÓS AMORÓS, E. "Acceso a la reproducción asistida..." op. cit, pp. 153-181.
} 


\subsection{La nueva situación generada por la Ley 20/2011, del Registro Civil}

El 21 de julio de 2011 se sancionó la Ley 20/2011, del Registro Civil (BOE no 175, de 22 de julio) en virtud de que la importancia del Registro Civil hacía necesario un nuevo modelo adaptado a los valores constitucionales y a la realidad actual social española.

No obstante la amplitud del cambio planteado por la nueva ley, esta nada dice, expresamente, respecto de la inscripción de los nacidos mediante TRA ${ }^{43}$, desperdiciándose la oportunidad para arrojar luz al entramado que plantea la LTRHA y uniformar la situación. Sin bien considero que hubiera sido necesaria una modificación profunda en la que quede reflejado y regulado el sistema y todos los cambios planteados por las TRA, nótese que la nueva ley ni siquiera hace referencia a la situación que introdujo el 7.3 LTRHA. La legislación registral no desarrolla legislativamente la posibilidad de inscripción de la doble filiación materna, aunque el nuevo art. 49, al regular el orden de los apellidos, emplea los términos neutros "progenitores" y "padres".

Ahora bien, no obstante no hacer referencia expresa a la inscripción de los nacidos mediante TRA, la ley sí genera una nueva situación debido a que elimina toda referencia a la filiación no matrimonial, que equipara plenamente a la matrimonial. No existe en la nueva ley precepto alguno que discrimine entre el acceso al Registro en los supuestos de filiación matrimonial frente a la no matrimonial, lo que evidencia que el sistema planteado por la LTRHA- que sí distingue entre filiación matrimonial y no matrimonial - debe reformarse; siendo conveniente que esta reforma se efectúe de manera apropiada, es decir, mediante su regulación en el CC, como se verá luego.

La complejidad de la nueva Ley de Registro Civil y el cambio radical respecto al modelo anterior aconsejan un extenso plazo de vacatio legis que se ha fijado en tres años; dentro de este plazo, de efectuarse la pertinente reforma de la filiación derivada de las TRA para su adaptación y armonización.

\section{Filiación derivada de las TRA: ¿un tercer tipo de filiación?}

En general, ${ }^{44}$ las leyes civiles distinguen entre filiación por naturaleza y por adopción; $;{ }^{45}$ atribuyen la paternidad sobre la base del matrimonio con la madre, la prueba genética de que alguien es padre biológico o bien por medio de la forma más típica de la paternidad social, la adopción. Mas,

\footnotetext{
${ }^{43}$ Respecto de la inscripción de nacimiento, se mantienen los criterios generales y se prevé la remisión de los datos del nacido a través de un documento oficial por los responsables de los centros sanitarios. A cada nacido se le abrirá un registro individual y le será asignado un código personal.

${ }^{44}$ El Código Civil de Qúebec sí distingue tres tipos de filiación: Cap. I: “De la filiation par le sang”; Cap. I.1: “De la filiation des enfants nés d'une procréation assistée" y Cap. II: “De l'adoption".

${ }^{45}$ En España, ni el CC español ni el CCCat contemplan de manera autónoma a la filiación derivada de las TRA. De los artículos 108.1 CC y 235-1 del CCCat se desprende que la filiación sólo puede tener lugar por naturaleza o por adopción. Pero, como se vio, si bien la Ley 25/2010, no incorpora un tercer tipo de filiación (art. 235-1). sí se ha visto en la necesidad de añadir el consentimiento para la procreación asistida a la lista de títulos de atribución de la filiación.
} 
como se pudo advertir a lo largo de este trabajo, los problemas que surgen con las TRA no se ajustan a ninguna de estas situaciones. ${ }^{46}$

Como se vio, mientras que en la filiación por naturaleza la determinación de la filiación tiende a asegurar la identidad personal en referencia a la realidad biológica; ${ }^{47}$ las TRA provocan la disociación del elemento genético, biológico y volitivo en distintas personas, pasando a ser este último el decisivo en la determinación de la filiación.

De esta manera, las TRA ponen en evidencia la necesidad de reestructurar el sistema que adopta el CC debido a que han dado lugar a un tercer tipo de filiación que se distingue de las 2 anteriores:

\subsection{Diferencia con la filiación por naturaleza}

La filiación derivada de las TRA se diferencia de la filiación por naturaleza porque en la primera no media acto sexual en la procreación; por lo que, a diferencia de la filiación por naturaleza, la filiación derivada de las TRA no se determina por la procreación, no deriva de ella.

En segundo lugar, porque en la filiación derivada de las TRA no siempre (en los casos de TRA heterólogas) el elemento genético es aportado por la misma persona que aporta el elemento volitivo. $^{48}$

Las dos diferencias anteriores conducen a una tercera: mientras en la filiación por naturaleza el vínculo se funda en el elemento biológico (que comprende el genético), en la filiación derivada de las TRA el vínculo se funda en el elemento volitivo; lo que, a su vez, hace que sea diferente su determinación y el régimen de impugnación.

Mientras que en la filiación por naturaleza la impugnación se funda en la falta de vínculo biológico, es lo que la habilita; en la filiación derivada de las TRA no es la falta de vínculo biológico que en realidad es genético - lo que habilita la impugnación, sino la falta del elemento volitivo. E régimen de impugnación se funda en el elemento volitivo lo que significa que, independientemente del vínculo biológico y/o genético, el que consintió no puede impugnar, o sólo puede impugnar quien no consintió.

Esta distinción es importante porque cuando las TRA son heterólogas siempre falta el vínculo genético, por lo que, ante las posibles impugnaciones que podrían plantearse por la falta del elemento genético, tiene que quedar claro y establecido legalmente que si se consintió no se puede impugnar.

\footnotetext{
${ }^{46}$ ROCA TRÍAS, E. “Filiación asistida y protección de derechos fundamentales". DS Vol. 7. 1999. Disponible en: http://www.ajs.es/downloads/vol0701.pdf. Compulsada el 27/08/2010

${ }^{47}$ Antes del surgimiento de las TRA, como regla, el vínculo filial era claro: madre cierta es, presunción de paternidad del marido de la madre, y reconocimiento; todos presupuestos fundados en el supuesto "vínculo biológico". KEMELMAJER DE CARLUCCI, A.; HERRERA, M.; LAMM, E. "La reproducción médicamente asistida. Mérito, oportunidad y conveniencia de su regulación." La Ley. 08/08/2011, 1

${ }^{48}$ En la filiación por naturaleza puede que el hombre no haya deseado tener un niño; independientemente de su falta de voluntad, la paternidad se le atribuye en virtud de haber aportado el material biológico (que en estos casos comprende el genético), elemento determinante.
} 
La filiación se determina sobre la base del consentimiento previamente prestado y ese consentimiento dado blinda la posibilidad de impugnar.

\subsection{Diferencia de la filiación por adopción}

La filiación derivada de las TRA se diferencia de la filiación por adopción porque, en esta última, siempre falta el vínculo genético entre los padres y el niño, situación que no siempre se presenta en la filiación derivada de las TRA (cuando son homólogas). De allí la preferencia por la filiación derivada de las TRA, en virtud de que estas permiten el "hijo genéticamente propio", es decir, que al menos uno de los que recurren a las TRA- o el que recurre si es una persona sola - esté genéticamente vinculado con el niño. ${ }^{49}$

Se asemejan porque en ambos supuestos el vínculo se determina por el elemento volitivo, pero se diferencian porque esa voluntad, que, como se vió, en la filiación derivada de las TRA debe ser manifestada a través de los consentimientos requeridos legalmente, debe prestarse con carácter previo al nacimiento. Consecuentemente, mientras en la filiación derivada de las TRA el elemento volitivo está presente desde el mismo origen de la persona, es decir, el niño nace y existe como consecuencia de esa voluntad; en la filiación por adopción el vínculo surge con posterioridad al nacimiento del niño, es decir, el niño ya existe cuando surge la voluntad de adoptarlo. ${ }^{50}$

Además, mientras que en la adopción el vínculo anterior (entre adoptado y la familia de origen) es biológico, cuando se recurre a las TRA heterólogas el vínculo entre el nacido y el donante es puramente genético. En la adopción el vínculo anterior es más fuerte, más profundo, implica o conlleva un plus que no está presente cuando se trata de un donante anónimo. ${ }^{51}$ Por esto es que,

\footnotetext{
${ }^{49}$ Además, pensar en la adopción como vía para acceso a la paternidad o maternidad es destacable por sí mismo, pero no pensar en hacerlo no puede ser objetado moralmente y menos aún si la objeción sólo recae sobre aquellos que tienen dificultades reproductivas y desean tener un hijo de otra manera. Las personas que quieren ser padres no tienen la obligación moral de pensar en la adopción como primera opción; en todo caso, es una decisión libre hacerlo o no. Asimismo, no es justo ni moral establecer un doble estándar para las personas fértiles o aquellas que no tienen problemas para concebir y otro para las que sí tienen problemas para concebir respecto de las formas de traer sus hijos al mundo y el deber moral de adoptar para unos y la exclusión del mismo para otros. Por otro lado, cabe mencionar las innumerables complicaciones legales y fácticas en los casos de adopción, que padecen incluso los que cumplen con las expectativas sociales de estar debidamente casados o en pareja estable, ser heterosexuales y encontrarse en condiciones laborales, económicas, sociales y ambientales buenas; en todos los otros casos que no cumplen con estos requisitos, no siempre explicitados por la justicia, los inconvenientes para adoptar se multiplican y suelen convertirse en impedimentos infranqueables. CAMACHO, J. M. Maternidad subrogada: una práctica moralmente aceptable. Análisis crítico de las argumentaciones de sus detractores. Disponible en:

http://www.fundacionforo.com/pdfs/maternidadsubrogada.pdf. Compulsada el 03/08/2011

${ }^{50}$ La adopción no conlleva en sí misma la creación de un nuevo ser, como supone la filiación derivada de las TRA, sino que se adopta un niño que ya existe.

${ }^{51}$ De allí que se pueda afirmar, como consecuencia de este nexo biológico, que en la adopción existe una "historia" previa, ha mediado un abandono, un desarraigo, y el vínculo con los adoptantes surge con posterioridad a todo esto. En la filiación derivada de las TRA, no se presenta esta "historia" previa, el vínculo con los "padres" surge en el instante en que se da comienzo a una nueva vida.
} 
mientras en la filiación por adopción se trata de conocer el origen biológico, en la filiación derivada de las TRA el derecho a conocer se refiere al origen genético, a los datos del donante como aportante de material genético. Entonces, si bien el nacido mediante TRA no debería ser privado legalmente del derecho a conocer su origen genético y consecuentemente debería tener la posibilidad de acceder a esa información, porque hace a su persona, a su dignidad y a su identidad y porque no puede ser discriminado respecto de otros niños que no han nacido mediante TRA; cabe tener en cuenta que no es una reivindicación de lo genético, sino la posibilidad de acceder a una información que, de alguna manera, hace que sea quién es.

En otras palabras, no se debería privar a los nacidos mediante TRA del derecho a conocer su origen genético, pero si dejar de tener en cuenta que se trata de acceder a la información relativa a quien fue un mero aportante de material genético - que además podría haber sido cualquier personapor lo que, si bien habría un derecho a conocer el origen genético, se debería "desmitificar" la importancia de este vínculo. ${ }^{52}$

Además, la adopción la constituye el juez, por lo que también se diferencian en cuanto a su determinación.

\subsection{Filiación derivada de las TRA}

Conforme se desprende de todo lo dicho, la filiación derivada de las TRA difiere de las otras dos, dando lugar a un tercer tipo de filiación que, como dije, es necesario que sea previsto y regulado por los Códigos Civiles.

Esta necesidad responde a que la filiación derivada de las TRA ha generado una problemática distinta a la de las otras dos filiaciones existentes, por lo que demanda soluciones propias. Se trata de situaciones nuevas que no pueden resolverse intentado imponer viejas reglas, como se pretende al remitir a las normas de las otras dos filiaciones, ${ }^{53}$ sino que se deben buscar y prever nuevas soluciones, acordes a las nuevas realidades y problemáticas que hoy existen y a las que en el futuro se presenten. El hecho de que la falta de regulación y especificidad lleve muchas veces a aplicar las normas de la filiación por naturaleza o por adopción, da lugar, en muchos casos, a soluciones injustas o poco claras, o a planteamientos abusivos o escrupulosos.

Como se vio, la LTRHA no sólo es poco clara y poco específica, sino también contradictoria. Además en muchos casos confiere distinto tratamiento a situaciones iguales, por lo que también resulta discriminatoria. Si a esto se le suma la nueva situación generada por la ley del Registro Civil, la necesidad de modificar la LTRHA es indiscutida y urgente, siendo conveniente que directamente se regule en el CC.

\footnotetext{
${ }^{52}$ Así, como sucedió con los niños adoptados, los nacidos mediante TRA perderían el interés en averiguar quién aportó el material genético.

${ }^{53}$ La necesidad de regular la filiación derivada de las TRA como un tercer tipo de filiación en el CC se hace aún más evidente cuando la propia LTRHA en su art. 7.1 remite a las Leyes civiles.
} 
Los nacimientos mediante TRA no son para nada excepcionales, y mucho menos luego de la admisión del matrimonio homosexual, dando lugar a nuevos modelos de familia. Son muchos los niños que han nacido y nacen producto de estas técnicas y esta importancia debe verse también traducida en el aspecto legal. Con el tiempo han emergido con claridad las notas propias de la filiación derivada de las TRA, por lo que no basta que esté prevista en unos pocos artículos de una ley, sino que, al igual que las otras dos filiaciones ya existentes, debe estar contemplada y expresamente regulada en el CC.

En definitiva, este tercer tipo de filiación, debe preverse de manera autónoma en el CC, mediante normas específicas que prevean claramente su determinación de manera uniforme para todos los casos, sus formalidades y requisitos, su régimen propio de impugnación, etc.

\section{Palabras finales}

Las TRA afectan el concepto de familia y seguramente continuarán afectándolo de maneras que aún no se pueden imaginar. Bajo estas circunstancias, considero que lo mejor es utilizar la noción de voluntad como la base o punto de partida para cualquier concepto de familia que pueda surgir.

Las TRA no sólo permiten que quien quiere ser padre o madre pueda serlo, habiendo brindado una solución a muchos supuestos de infertilidad; sino que además permiten que madre o padre sea entonces quien ha querido serlo.

Ser padre o madre es mucho más que un vínculo genético o biológico: es querer ser padre o querer ser madre; y eso es precisamente lo que permite la filiación derivada de TRA al prever un sistema basado en la voluntad.

\section{Bibliografía}

- ALKORTA IDIÁKEZ, I. Regulación jurídica de la medicina reproductiva. Derecho español y comparado. Thomson Aranzadi. Navarra. 2003.

- BERCOVITZ RODRIGUEZ CANO, R. "La filiación inducida y las clasificaciones legales". Ponencia presentada al II Congreso Mundial Vasco, celebrado en Vitoria (28-IX a 2-X-1987), en La filiación a finales del siglo XX. Problemática planteada por los avances científicos en materia de reproducción humana. Editorial Trivium. Madrid. 1988.

- CAMACHO, J. M. Maternidad subrogada: una práctica moralmente aceptable. Análisis crítico de las argumentaciones de sus detractores. Disponible en: http://www.fundacionforo.com/pdfs/maternidadsubrogada.pdf. Compulsada el 03/08/2011

- FÁBRega RUIZ, C. F. Biología y filiación. Aproximación al estudio jurídico de las pruebas biológicas de paternidad y de las técnicas de reproducción asistida. Comares. Granada, 1999.

- FARNÓS AMORÓS, E. "Acceso a la reproducción asistida por parejas del mismo sexo en España: estado de la cuestión, propuestas y retos". Revista de Derecho de Familia. Núm. 49. Mayo 2011. 
- FARNÓS AMORÓS, E. Tesis doctoral "Ruptura del projecte parental i disposició dels preembrions", defendida el 5 de mayo de 2010 en la Universitat Pompeu Fabra, pp. 1-594: http://www.tesisenred.net/TESIS UPF/AVAILABLE/TDX-0902110-085844//tef.pdf

- KEMELMAJer de CARLUCCI, A.; HeRRERA, M.; LAMM, E. "La reproducción médicamente asistida. Mérito, oportunidad y conveniencia de su regulación." La Ley. 08/08/2011, 1

- OBSERVATORIO DE BIOÉTICA Y DERECHO DE LA UNIVERSIDAD DE BARCELONA. Documento sobre selección de sexo. CASADO, M. (Coord.) Signo. Barcelona. 2003. Disponible en:

http://www.pcb.ub.es/bioeticaidret/archivos/documentos/Seleccion de sexo.pdf. Compulsada el $\underline{27 / 08 / 2010}$

- OBSERVATORIO DE BIOÉTICA Y DERECHO DE LA UNIVERSIDAD DE BARCELONA. Reedición y análisis del impacto normativo de los documentos del Observatorio de Bioética y Derecho sobre reproducción asistida. CASADO, M. (Coord.) Signo. Barcelona. 2008. Disponible en:

http://www.pcb.ub.es/bioeticaidret/archivos/documentos/Reedicion Reprod-Asistida.pdf. Compulsado el 17-07-2011.

- RIVERO HERNÁNDEZ, F. "La investigación de la mera relación biológica en la filiación derivada de fecundación artificial". Ponencia presentada al II Congreso Mundial Vasco, celebrado en Vitoria (28-IX a 2-X-1987), en La filiación a finales del siglo XX. Problemática planteada por los avances científicos en materia de reproducción humana. Editorial Trivium. Madrid. 1988.

- ROCA TRÍAS, E. "Filiación asistida y protección de derechos fundamentales". DS Vol. 7. 1999. Disponible en: http://www.ajs.es/downloads/vol0701.pdf. Compulsada el 27/08/2010

- SERRANO ALONSO, E. "Aspectos de la fecundación artificial". Actualidad Civil. Núm. 107. 1999. 